\title{
THE NEURAL BASIS OF SUPPRESSION AND AMBLYOPIA IN STRABISMUS
}

\author{
FRANK SENGPIEL and COLIN BLAKEMORE \\ Oxford
}

\begin{abstract}
SUMMARY
The neurophysiological consequences of artificial strabismus in cats and monkeys have been studied for 30 years. However, until very recently no clear picture has emerged of neural deficits that might account for the powerful interocular suppression that strabismic humans experience, nor for the severe amblyopia that is often associated with convergent strabismus. Here we review the effects of squint on the integrative capacities of the primary visual cortex and propose a hypothesis about the relationship between suppression and amblyopia. Most neurons in the visual cortex of normal cats and monkeys can be excited through either eye and show strong facilitation during binocular stimulation with contours of similar orientation in the two eyes. But in strabismic animals, cortical neurons tend to fall into two populations of monocularly excitable cells and exhibit suppressive binocular interactions that share key properties with perceptual suppression in strabismic humans. Such interocular suppression, if prolonged and asymmetric (with input from the squinting eye habitually suppressed by that from the fixating eye), might lead to neural defects in the representation of the deviating eye and hence to amblyopia.
\end{abstract}

Strabismus is one of the most frequent visual disorders in human beings, with a childhood incidence of about $6 \% .{ }^{1}$ Various categories can be discerned clinically, depending on the age of onset, state of fixation, presumed aetiology, etc. (for reviews see Duke-Elder ${ }^{2}$ and von Noorden ${ }^{3}$ ). Among them, esotropia, or convergent squint, is the commonest form, with a relative prevalence of about $67 \% .^{1}$ In the majority of cases, it is associated with unilateral fixation and amblyopia in the nonfixating eye, i.e. a deficit in visual acuity, in the absence of any recognisable ocular pathology, which persists even when refractive errors have been corrected. There is a lower incidence of amblyopia

Correspondence to: Frank Sengpiel, University Laboratory of Physiology, Parks Road, Oxford OX1 3PT, UK. Fax: +44 (01865) 272 488. e-mail: sengpiel@physiol.ox.ac.uk. with exotropia (divergent squint), possibly because of the higher prevalence of alternating fixation and/ or, frequently, the later onset of deviation. Stereopsis is either absent or very deficient in all forms of strabismus, whether or not one eye is amblyopic. In addition, there are a variety of other deficits in binocular visual function.

\section{NEURAL SUBSTRATES OF AMBLYOPIA}

For 30 years, artificial (surgically or optically induced) squint in cats and monkeys has served as an animal model of human strabismus. ${ }^{4}$ Just as in humans, animals with strabismus have impaired stereopsis ${ }^{5,6}$ and can become amblyopic in the deviating eye. ${ }^{7-10}$ However, despite considerable efforts, neurophysiological studies have failed until very recently to reveal central deficits that might account for either the severe acuity loss that often occurs in the deviating eye of strabismic humans and animals or for some of the more subtle defects of binocular function. Most investigators have simply studied the responses of individual cortical neurons in the primary visual cortex (V1) to monocular stimulation: strabismus of early onset was found to cause a breakdown of conventional 'binocularity'. Most cells in the visual cortex of strabismic cats ${ }^{11-16}$ and monkeys $6,17,18$ can be driven through only one eye, either left or right, seldom through both, and the slight variation in cortical ocular dominance across the cortex seen in normal animals becomes transformed in sharply defined ocular dominance (OD) columns. There is indirect evidence that this also holds true for V1 of strabismic humans. ${ }^{19}$ This loss of 'binocular' neurons is assumed to underlie the defects of binocular summation and stereopsis in strabismic animals ${ }^{5,6}$ and humans. ${ }^{20,21}$

Visual acuity, as assessed with conventional optotypes, depends on both the detection and the localisation of variations of contrast in the retinal image. For an emmetropic eye, visual acuity is normally determined by spatial sampling of the 
image in the eye. Indeed, for humans and monkeys, acuity in the central field appears to be limited by the mosaic of foveal cones. ${ }^{22}$ In principle, then, the reduction in acuity that characterises amblyopia could be due to one or a combination of three different causes: (1) a decrease in the number of sampling channels at some point in the retina or visual pathway, leading to undersampling of the image and hence an incomplete central representation of the visual stimulus; (2) coarsening of the 'grain' of spatial sampling, e.g. as a result of convergence of signals on to central neurons, leading to a decrease in neural 'acuity'; or (3) some kind of 'scrambling' of the central representation, causing positional uncertainty in that representation. ${ }^{23-25}$

In the case of deprivation amblyopia and anisometropic amblyopia, there is a partial 'disconnection' of the affected eye from the primary visual cortex. Whereas in normal cats and monkeys the vast majority of cortical neurons respond to stimulation through either eye, in animals that have been reared with one eye closed or defocused, the proportion of cortical neurons responding through the affected eye is much reduced. ${ }^{17,26-29}$ Thus, in these kinds of amblyopia the image might be undersampled at the level of the cortex (depending on the degree of oversampling, if any, in the normal animal). On the other hand, the evidence for neural undersampling in strabismus is much less consistent. Some reports of cortical cells in strabismic monkeys ${ }^{17,18}$ and (less strikingly) cats $^{30,31}$ have described a bias in the ocular dominance of cortical neurons, fewer responding through the deviating than the normal eye. However, most studies, 6,11-14,16 even in cats and monkeys with demonstrated behavioural amblyopia, ${ }^{15,25}$ have reported roughly equal numbers of neurons responding through the squinting and the non-squinting eye.

Similarly, there is much clearer evidence for a deficit in neural 'acuity' in deprivation and anisometropic amblyopia than in strabismus. ${ }^{25}$ After early occlusion or defocus of one eye, the minority of cells in the cortex that still respond through that eye tend to have diffuse, insensitive receptive fields and hence have poor spatial resolution and sensitivity to contrast. ${ }^{28,29,32}$ On the other hand, several studies on strabismic cats $^{10,33,34}$ and monkeys, ${ }^{25}$ even with proven amblyopia, have revealed that cortical cells responding through the deviating eye have, at best, spatial resolving power and contrast sensitivity indistinguishable from the best neural acuity of cells driven through the normal eye. However, in cats with strabismic amblyopia, Crewther and Crewther ${ }^{15}$ reported a small reduction in the average neural acuity of cortical cells through the squinting eye, and Movshon and Kiorpes ${ }^{35}$ have seen a similar modest effect on neural acuity in esotropic monkeys.
In earlier reports, Ikeda and her colleagues had described much more dramatic reductions in neural acuity in strabismic cats, for cells of the lateral geniculate nucleus (LGN) ${ }^{36}$ and for retinal ganglion cells. $^{37}$ However, later studies established that behavioural amblyopia can occur with no detectable effects in the retina ${ }^{38}$ or the LGN. ${ }^{33,39}$

Errors in the central representation of the relative positions of parts of the image may be the cause of several perceptual problems experienced in amblyopia, most obviously the spatial distortion of the visual scene $e^{40}$ but also impaired vernier acuity ${ }^{23,41}$ and the spatial interference of contours, or 'crowding', that many amblyopic humans complain of. There is some evidence of 'scrambling' of receptive fields in V1 of cats with deprivation amblyopia. ${ }^{42}$ Unusually large ${ }^{43}$ and scattered receptive fields ${ }^{44}$ have also been reported for neurons in V1 of strabismic cats. However, the vast majority of studies suggest that the monocular receptive field properties differ little from those in normal cats ${ }^{14,16,30,33,45-47}$ except, perhaps, in the representation of the extreme nasal visual field of the deviating eye in esotropic animals. $^{47}$

More recent studies have focused on the possible effects of strabismus on the integrative capacities of the visual cortex, and it is in this area where substantial anomalies have recently been described. In the normal cortex, neurons with similar stimulus preferences tend to fire impulses synchronously when visually stimulated simultaneously, ${ }^{48,49}$ even if their receptive fields do not overlap. ${ }^{50}$ This synchronisation, which normally occurs whether the two cells are activated with stimuli falling in the same eye or in different eyes, has been hypothesised to play an important role in 'binding' the activity of the various feature-detecting neurons that respond to a particular global contour, surface or object into a coherent representation, and to distinguish that representation from those for other, nearby contours, surfaces or objects (for a review, see Singer ${ }^{51}$ ). Now, in V1 of strabismic cats, neurons dominated by one eye tend not to synchronise their firing with cells dominated by the other eye. ${ }^{10,52}$ This loss of synchronisation between neurons in neighbouring OD columns correlates with the fact that the long-range intrinsic connectivity which is such a striking feature of normal V1 is specifically reduced between OD columns for different eyes in strabismic cats. ${ }^{53}$ Moreover, in esotropic cats with behaviourally verified amblyopia, neurons dominated by the normal eye exhibit stronger synchronisation of responses with each other than do those dominated by the amblyopic eye. This difference is most pronounced for gratings of high spatial frequency, even though the amplitude of responses to such stimuli through the amblyopic eye is not reduced. ${ }^{10}$ 
This kind of impairment of temporal integration of inputs from an amblyopic eye may contribute to the reduced visual acuity, the perceptual distortions and to the crowding phenomenon.

\section{SUPPRESSION AND AMBLYOPIA}

Strabismus of substantial angle invariably precipitates a disturbance or disruption of binocular vision, because the two images of each feature in the visual scene fall on entirely non-corresponding points in the two retinae. Despite the resulting potential for diplopia and confusion, after strabismus of early onset the visual system usually adapts to the situation, and single vision is maintained, either through anomalous retinal correspondence, in which functional correspondence is shifted to match the angle of squint (for reviews, see Nelson ${ }^{54}$ and Schor $^{55}$ ) or through suppression of vision in the non-fixating eye.

It has frequently been suggested that strabismic amblyopia might be precipitated by interocular suppression. ${ }^{56-59}$ Support for this hypothesis comes from the finding that variations in the depth of suppression across the visual field are well correlated with acuity deficits both in human subjects with alternating fixation ${ }^{58}$ and in esotropic amblyopes with chronic suppression of vision in the amblyopic eye. ${ }^{57,59}$

\section{THE NEURAL BASIS OF STRABISMIC SUPPRESSION}

$\mathrm{We}^{16}$ have investigated the possibility that altered cortical binocular interaction, related to strabismic suppression, might lie at the heart of many of the anomalies brought about by ocular misalignment. We studied the responses of single neurons to drifting gratings in the primary visual cortex of anaesthetised paralysed cats. In normal animals, most cells display strong binocular facilitation when single, moving bars of similar orientation are presented simultaneously to the receptive fields in the two eyes, as long as the relative positions of the images on the two retinae are optimised for cells that have a strong preference for a particular disparity. Such excitatory interaction may be essential for binocular fusion of corresponding features and for stereoscopic vision. ${ }^{60,61}$ Repetitive grating patterns of matched orientation also usually produce facilitation when the relative disparity or spatial phase of the individual bars of the gratings is optimised. ${ }^{62,63}$ However, the response to an optimally oriented grating being presented in one eye is, for a majority of cells, reduced significantly by the sudden appearance of a grating of substantially different orientation in the other eye. We have suggested that this orientation-dependent interocular suppression may underlie the psychophysical phenomenon of binocu- lar rivalry, ${ }^{64,65}$ and support for this hypothesis comes from similar, recent findings in V1 of awake behaving macaques. 66

In contrast, in V1 of five adult cats that had been tenotomised just after eye-opening, to induce either exotropia or esotropia, only $9 \%$ of cells exhibited any significant binocular facilitation for dichoptic gratings of the same orientation in the two eyes (even though $31 \%$ of the neurons were weakly binocular in the conventional sense, i.e. excitable through either eye alone). Another $36 \%$ of neurons showed no binocular interaction at all, while for $55 \%$ of all cells, responses elicited through the cell's dominant eye were suppressed dramatically by presentation of gratings of any orientation to the cell's non-dominant or 'silent' eye. The reduction in response was roughly the same (about $40 \%$ on average) whether the two gratings were orthogonal or iso-oriented. ${ }^{16}$ This characteristic is clearly reminiscent of pathological suppression in strabismic humans, which also varies very little in strength with stimulus orientation. ${ }^{67}$

Interestingly, in the representation of the central visual field in $\mathrm{V} 1$, where we made all our recordings, the depth of interocular suppression did not seem to depend in any obvious way on the direction and absolute angle of squint.

We are now extending our investigations to strabismic monkeys and find non-orientation-specific suppression, similar to that seen in cats. ${ }^{34} \mathrm{We}$ recorded from one adult rhesus monkey (Macaca mulatta) after myotomy of the lateral rectus of the right eye at the age of 19.5 weeks ( 4.5 months), which had developed an esotropia of about $30^{\circ}$. This animal fixated unilaterally with the non-operated eye and, in a preferential looking test, had visual acuity 2.4 octaves lower in the deviating eye than in the normal eye. Despite the relatively late onset of squint in this monkey, the loss of binocularity was severe: only 22 of $55 \mathrm{~V} 1$ neurons $(40 \%)$ were excitable through either eye, while 33 cells $(60 \%)$ were strictly monocular by conventional tests. Of 25 quantitatively tested units (all with receptive field centres within $2^{\circ}$ of the fovea) 11 showed significant binocular interactions. While binocular facilitation for contours of similar orientation in the two eyes was seen for just two cells, nine cells exhibited orientation-independent interocular suppression; six of them were dominated by the normal eye, three by the operated eye. An extreme example, with a response reduction of up to $97 \%$, is illustrated in Fig. 1. Remarkably, all cells showing clear suppression were located in layers $4 \mathrm{~B}, 4 \mathrm{C} \alpha$ and 6 , and none was found in the supragranular layers; in cat V1 suppression occurred among equal proportions of cells in all layers outside layer 4. The laminar distribution of orientation-independent suppression in monkey V1 may have to be interpreted in the 
A
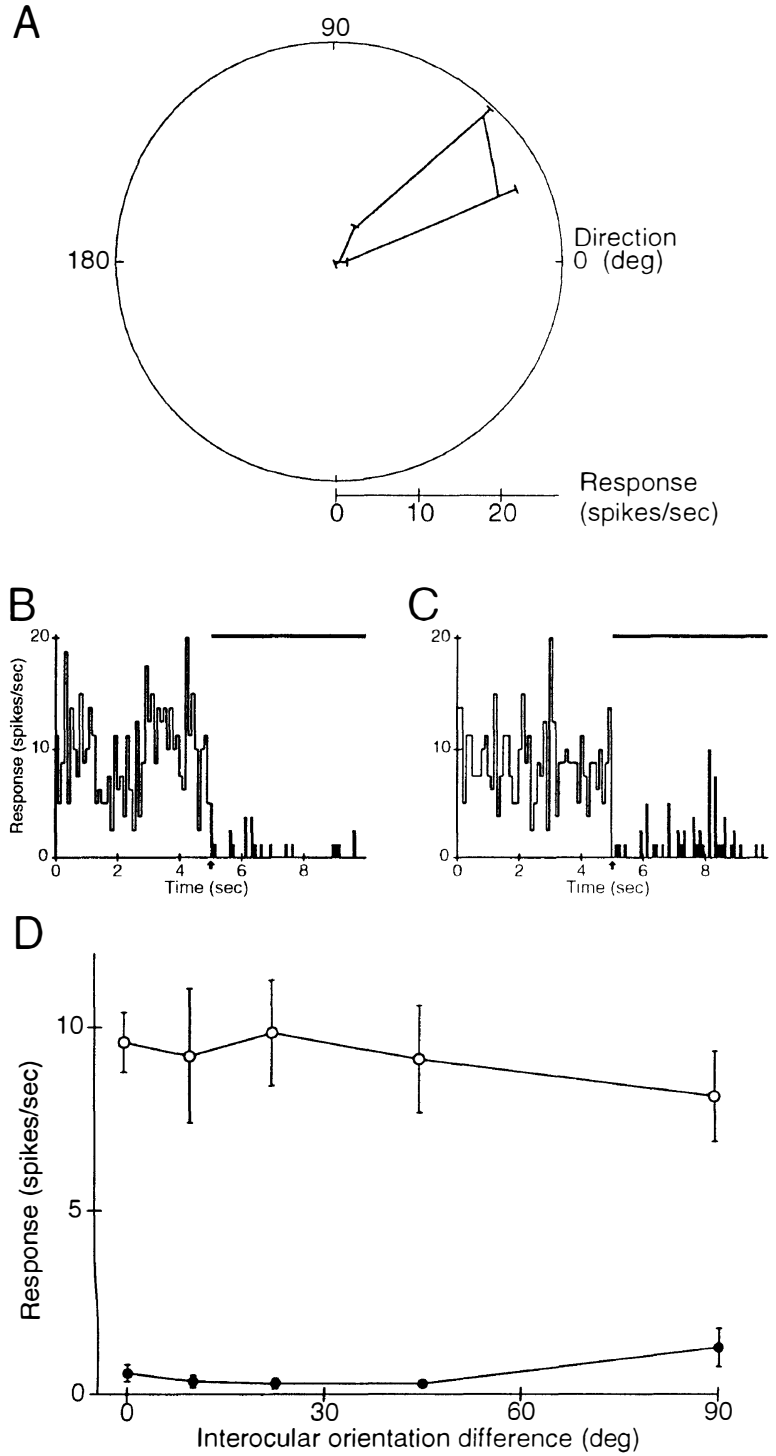

context of the generally higher laminar specificity of certain response properties. The magnocellular ('M') layers of the LGN project specifically to layer $4 \mathrm{C} \alpha$, and thence to 4B, as well as to layer 6. Perhaps, then, interocular suppression in the monkey (and presumably in humans too) is more pronounced for neurons of the magnocellular pathway, which is indeed thought to be more concerned with stereopsis than the parvocellular ('P') pathway. ${ }^{68}$

In strabismic humans, suppression is strongest in the fovea of the deviating eye $\mathrm{e}^{57,58}$ and much stronger in the nasal hemiretina of an esotropic eye and in the temporal hemiretina of an exotropic eye than in the opposite hemiretinae, which do not 'compete' with the fovea of the fixating eye. ${ }^{57,69}$ It is also in the visual hemifields corresponding to these 'competing' hemiretinae that acuity deficits are most pronounced. ${ }^{57}$ In contrast, in parts of the peripheral visual field, some binocular function is often maintained $^{58}$ and acuity in the amblyopic eye is close to
Fig. 1. Orientation-independentinterocular suppression in a layer 6 simple cell recorded from V1 of an esotropic monkey, exclusively driven through the non-operated (contralateral) eye. (A) Polar plot of orientation selectivity, showing mean responses (+1 SEM) during monocular stimulation through the dominant (contralateral) eye, with drifting gratings of optimal spatial frequency, as a function of the direction of movement (orthogonal to the orientation of the grating). (B), (C) Peri-stimulus time histograms of responses, accumulated over eight trials, to dichoptic gratings of identical $(B)$ and orthogonal orientations $(C)$, respectively. The cell was continuously stimulated through the dominant eye with a grating of optimal orientation (direction of drift $45^{\circ}$ ) and spatial frequency. Periods of monocular stimulation, each lasting 5 seconds, were interleaved with 5 seconds periods during which a second grating of the same spatial frequency but varying in orientation from presentation to presentation appeared in the non-dominant (operated) eye. The arrows mark the onset of binocular exposure, which continued for the 5 second periods indicated by the filled bars above the histograms; bin width, 100 milliseconds. (D) Full results of the binocular interaction protocol. The dominant eye was continuously stimulated with an optimal 'conditioning' grating (contrast 0.18), while other gratings (contrast always 0.7) appeared intermittently in the 'silent' eye at five different orientations, over a $90^{\circ}$ range, clockwise from that of the 'conditioning' stimulus. Each filled circle plots the mean response ( $\pm 1 S E M)$ during binocular stimulation with a particular combination of gratings, while the corresponding unfilled circle plotted at the same position on the abscissa shows activity averaged over the immediately preceding periods of monocular stimulation. The gratings presented to the 'silent' eye, incapable of exciting the cell directly, produced very strong suppression (response reduced, compared with the monocular level, by $>90 \%$ ) whatever their orientation.

normal. ${ }^{57} \mathrm{We}$ are beginning to explore whether neuronal suppression in strabismic cats and monkeys also varies across the representation of the visual field. We recorded from $\mathrm{V} 1$ in a 'microstrabismic' cat (distinct but transient esotropia after surgery, with ocular misalignment so small as to be unmeasurable in the adult $t^{31}$ ) and found that, of 18 neurons with receptive fields within $3^{\circ}$ of the area centralis, 11 showed significant interocular suppression independent of stimulus orientation, while 9 cells, whose receptive field centres were about $10^{\circ}$ below the centre of the visual field, all exhibited normal binocular facilitation for iso-oriented dichoptic gratings (Sengpiel, Harrad, Freeman and Blakemore, unpublished observation).

It should be noted that, in strabismic humans, suppression is not confined to the central retina of the deviating eye but also occurs in the fixating eye (in particular near the fovea) during foveal stimulation of the deviating eye. ${ }^{56,58}$ This situation closely 
resembles that created by our stimulation paradigm where gratings were always presented at corresponding positions in the two retinae, and mostly near the centre of the visual field. Therefore, it may not be surprising that interocular suppression at the neuronal level was usually symmetric between the eyes: in three of five cats the depth of suppression for cells dominated by the normal eye was, on average, comparable to that for cells dominated by the deviating eye. Moreover, we do not know whether the animals in our study had in fact developed amblyopia in the operated eye. In view of recently published behavioural data ${ }^{10}$ one might imagine that most of them were not amblyopic or only mildly so. However, at least some of the animals habitually fixated with one eye and were unable to maintain steady fixation with the squinting eye during a cover test. Also, a study on an awake monkey with lateonset esotropia and no amblyopia showed that for some neurons in $\mathrm{V} 1$, suppression of responses elicited through one eye can be observed only when the other eye is used for fixation. ${ }^{70}$

Only one cat displayed a clear asymmetry of neural suppression among the sample of neurons that we studied; in this animal the deviating eye was capable of suppressing responses elicited through the normal eye but not vice versa. ${ }^{16}$ Though apparently counter-intuitive, this finding may reflect the inverse relationship between severity of amblyopia and depth of suppression that has been reported for strabismic humans: ${ }^{67}$ this cat was the most likely among the animals studied to have developed amblyopia in the deviating eye, with a small-angle esotropia $\left(4^{\circ}\right)$ and a bias in ocular dominance in favour of the normal, fixating eye. It is conceivable that, once deep amblyopia is established in one eye (and binocular vision effectively superseded by monocular vision through the dominant eye), suppression actually decreases: teleologically, there may no longer be a need for it; and there may be no substrate for the underlying interactions. Our own work on dark-reared cats ${ }^{71}$ as well as studies on cats with optically induced squint ${ }^{72}$ or monocular lidsuture $^{73}$ indicate that, the longer input from the two eyes is dissociated or indeed prevented altogether, the weaker any binocular interactions become. It appears that binocular facilitation is most susceptible to manipulations that decorrelate signals from the two eyes; after the loss of facilitation, suppression prevails until eventually inhibitory interactions weaken too.

On balance there is good evidence that suppressive interactions of the sort observed in the visual cortex of strabismic animals form the neural substrate for perceptual suppression in strabismic humans. It is tempting to speculate that such interocular suppression in V1, if both prolonged and asymmetric, such that input from the squinting eye is habitually held suppressed by that from the fixating eye, eventually leads to amblyopia in the more frequently suppressed eye. The maturation of the visual cortex, which normally leads to increasing spatial resolution and contrast sensitivity of individual cells, as well as to the maintenance and strengthening of binocularity, is thought to depend on 'Hebbian' synaptic 'learning' in which coincidence of presynaptic and postsynaptic activity leads to the selective strengthening of the activated synapses (for a review, see Rauschecker ${ }^{74}$ ). If, in a squinting animal, the neurons in the OD columns with input from the deviating eye are held constantly inhibited by suppression from the other eye's OD columns, their inactivity might interfere with the process of synaptic learning. This hypothesis could account for disturbances of maturation for cortical neurons connected to a squinting eye, despite the fact that the eye itself has a wellfocused image much of the time. However, the way in which one eye commonly becomes dominant for fixation (and suppression becomes asymmetrical), and hence amblyopia occurs in esotropia, but very rarely in exotropia, remains a matter of debate.

\section{NEUROANATOMICAL BASIS FOR STRABISMIC SUPPRESSION}

We believe that inhibitory interactions in the visual cortex of strabismic subjects are closely related, if not identical to, interocular interactions in the normal visual cortex, where explicit interocular suppression is normally triggered only by stimuli that differ substantially in orientation. Both forms of neuronal interocular suppression are characterised by disparity independence, broad spatial frequency tuning and divisive response gain reduction. ${ }^{64}$ They are also of similar strength: in response to orthogonally oriented dichoptic gratings, a population of 116 neurons from ten normal cats exhibited a mean suppression of $40.6 \%( \pm 2.9 \%$ SEM $)$, while 110 cells from seven strabismic animals were suppressed by an average of $39.4 \%$ ( $\pm 2.6 \%$ SEM $)$. These similarities led us to suggest that the orientation selectivity of binocular interaction in normal cortex is generated by the sum of suppression that is independent of relative orientation plus binocular facilitation only for matched orientations, and that the latter is specifically lost in strabismus. This hypothesis is supported by our recent finding that even in the normal cortex the presentation in one eye of a grating of a spatial frequency too high or low to elicit an excitatory response can trigger suppression of responses being produced by an optimum grating in the other eye, and that this suppression by a non-excitatory grating is independent of its orientation. ${ }^{75}$ This strongly suggests that the binocular facilitation for matched stimuli, thought to underlie fusion and stereopsis, is 

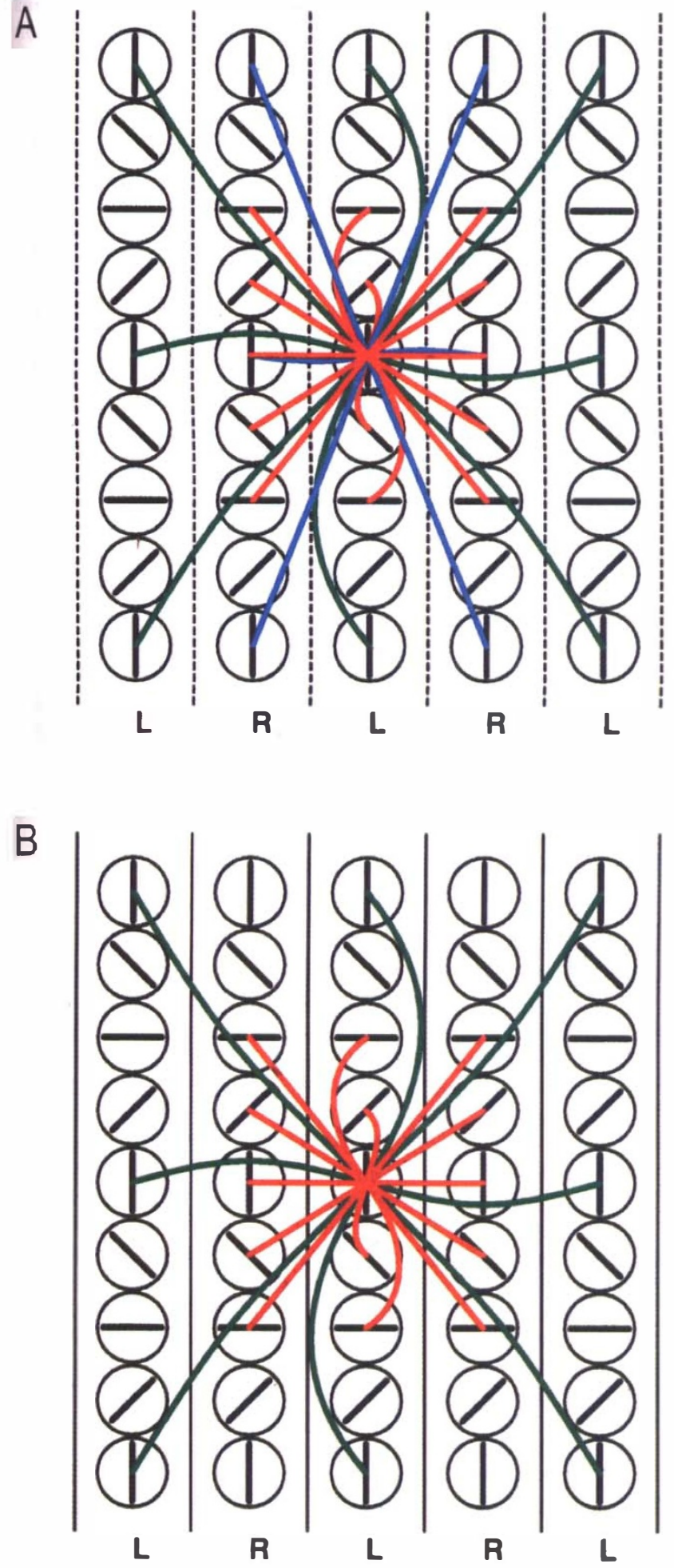

superimposed on non-selective inhibitory interaction between the two eyes.

A possible anatomical substrate for the excitatory and inhibitory binocular interactions postulated above is schematically illustrated in Fig. 2. Blue and green lines symbolise excitatory connections between clusters of cells of same-eye dominance and opposite-eye dominance, respectively; red lines represent inhibitory connections. In the normal
Fig. 2. Schematic diagram of intrinsic horizontal connections that might underlie binocular interaction in V1 of normal $(A)$ and strabismic $(B)$ cats. A surface view of orientation and ocular dominance $(O D)$ domains is shown. Parallel slabs or 'columns' marked ' $L$ ' and ' $R$ ' represent left-eye and right-eye OD columns, respectively. In normal animals, these columns are only weakly segregated in supraand infragranular layers (symbolised by the interrupted lines in A), while they are clearly delineated in strabismic animals (continuous lines in B). Columns of cells with similar orientation preference are depicted as circles with an oriented line inside. Green and blue lines represent excitatory projections, which selectively connect neurons of similar orientation preference, respectively, within and between neighbouring $O D$ columns, while red lines show widespread, non-selective inhibitory connections. See text for further explanation. visual cortex (A), clustered excitatory intrinsic connections between regions of similar orientation preference $^{76,77}$ may mediate disparity-sensitive binocular facilitation. Long-range inhibitory connections are much more diffuse ${ }^{78}$ and also link different orientation domains. ${ }^{79,80}$ In strabismic animals (B), excitatory intrinsic connections between neighbouring OD columns are selectively lost,$^{53}$ leaving only inhibitory projections in the majority of cells. We 
believe that such non-specific intracortical inhibition forms the neural basis of the pronounced interocular suppression seen in strabismic subjects.

We thank Richard Harrad for helpful comments on the manuscript. This work was supported by the Medical Research Council and the Oxford McDonnell-Pew Centre for Cognitive Neuroscience. F.S. holds a Fellowship at Magdalen College, Oxford.

Key words: Strabismus, Amblyopia, Suppression, Binocularity, Primary visual cortex, Monkey, Cat.

\section{REFERENCES}

1. Graham PA. The epidemiology of strabismus. Br J Ophthalmol 1974;58:224-31.

2. Duke-Elder S, Wybar KC. Ocular motility and strabismus. In: Duke-Elder S, editor. System of ophthalmology. London: Henry Kimpton, 1973.

3. von Noorden GK. Binocular vision and ocular motility: theory and management of strabismus. St Louis: CV Mosby, 1990.

4. Mitchell DE. Animal models of human strabismic amblyopia: some observations concerning the interpretation of the effects of surgically and optically induced strabismus in cats and monkeys. In: Shinkman PG, editor. Advances in neural and behavioural development. Norwood, NJ: Ablex Publishing, 1988: 209-69.

5. von Grünau MW. Binocular summation and the binocularity of cat visual cortex. Vision Res 1979;19: 813-6.

6. Crawford MLJ, Smith EL III, Harwerth RS, von Noorden GK. Stereoblind monkeys have few binocular neurons. Invest Ophthalmol Vis Sci 1984;25:779-81.

7. von Noorden GK, Dowling JE. Experimental amblyopia in monkeys. II. Behavioural studies in strabismic amblyopia. Arch Ophthalmol 1970;84:215-20.

8 Ikeda H, Jacobson SG. Nasal field loss in cats reared with convergent squint: behavioural studies. J Physiol (Lond) 1977;270:367-81.

9. von Grünau MW, Singer W. Functional amblyopia in kittens with unilateral exotropia. II. Correspondence between behavioural and electrophysiological assessment. Exp Brain Res 1980;40:305-10.

10. Roelfsema PR, König P, Engel AK, Sireteanu R, Singer W. Reduced synchronization in the visual cortex of cats with strabismic amblyopia. Eur J Neurosci 1994;6:1645-55.

11. Hubel DH, Wiesel TN. Binocular interaction in striate cortex of kittens reared with artificial squint. J Neurophysiol 1965;28:1041-59.

12. Blakemore $\mathrm{C}$. The conditions required for the maintenance of binocularity in the kitten's visual cortex. J Physiol (Lond) 1976;261:423-44.

13. Van Sluyters RC, Levitt FB. Experimental strabismus in the kitten. J Neurophysiol 1980;43:686-99.

14. Singer W, von Grünau MW, Rauschecker JP. Functional amblyopia in kittens with unilateral exotropia. I. Electrophysiological assessment. Exp Brain Res 1980;40:294-304.

15. Crewther DP, Crewther SG. Neural site of strabismic amblyopia in cats: spatial frequency deficit in primary cortical neurons. Exp Brain Res 1990;79:615-22.

16. Sengpiel F, Blakemore C, Kind PC, Harrad R. Interocular suppression in the visual cortex of strabismic cats. J Neurosci 1994;14:6855-71.

17. Baker FH, Grigg P, von Noorden GK. Effects of visual deprivation and strabismus on the response of neurons in the visual cortex of the monkey, including studies on the striate and prestriate cortex in the normal animal. Brain Res 1974;66:185-208.

18. Crawford MLJ, von Noorden GK. The effects of shortterm experimental strabismus on the visual system in Macaca mulatta. Invest Ophthalmol Vis Sci 1979;18: 496-505.

19. Blake R, Cormack RH. Psychophysical evidence for a monocular visual cortex in stereoblind humans. Science 1979;203:274-5.

20. Lema S, Blake R. Binocular summation in normal and stereoblind humans. Vision Res 1977;17:691-5.

21. Levi DM, Harwerth RS, Smith EL III. Humans deprived of normal binocular vision have binocular interactions tuned to size and orientation. Science 1979;206:852-4.

22. Jacobs DS, Blakemore C. Factors limiting the postnatal development of visual acuity in the monkey. Vision Res 1988;28:947-58.

23. Levi DM, Klein SA. Vernier acuity, crowding and amblyopia. Vision Res 1985;25:979-91.

24. Hess RF, Field DJ, Watt RJ. The puzzle of amblyopia. In: Blakemore $\mathrm{C}$, editor. Vision: coding and efficiency. Cambridge: Cambridge University Press, 1990:267-80.

25. Blakemore C, Vital-Durand F. Different neural origins for 'blur' amblyopia and strabismic amblyopia. Ophthalmic Physiol Opt 1992;12:83.

26. Wiesel TN, Hubel DH. Single-cell responses in striate cortex of kittens deprived of vision in one eye. J Neurophysiol 1963;26:1003-17.

27. Blakemore C, Garey LJ, Vital-Durand F. The physiological effects of monocular deprivation and their reversal in the monkey's visual cortex. J Physiol (Lond) 1978;283:223-62.

28. Eggers HM, Blakemore C. Physiological basis of anisometropic amblyopia. Science 1978;201:264-7.

29. Movshon JA, Eggers HM, Gizzi MS, Hendrickson AE, Kiorpes L, Boothe RG. Effects of early unilateral blur on the macaque's visual system. III. Physiological observations. J Neurosci 1987;7:1340-51.

30. Mower GD, Burchfield JL, Duffy FH. Animal models of strabismic amblyopia: physiological studies of visual cortex and the lateral geniculate nucleus. Dev Brain Res 1982;5:311-27.

31. Sireteanu R, Singer W, Fronius M, Greuel JM, Best J, Fiorentini A, et al. Eye alignment and cortical binocularity in strabismic kittens: a comparison between tenotomy and recession. Vis Neurosci 1993; 10:541-9.

32. Blakemore C. Maturation of mechanisms for efficient spatial vision. In: Blakemore $\mathrm{C}$, editor. Vision: coding and efficiency. Cambridge: Cambridge University Press, 1990:254-66.

33. Blakemore C, Eggers HM. Animal models for human visual development. In: Cool SJ, Smith EL III, editors. Frontiers in visual science. New York: Springer, 1978:651-9.

34. Sengpiel F. Mechanisms of binocular integration in the mammalian primary visual cortex. DPhil thesis, University of Oxford, 1994.

35. Movshon JA, Kiorpes L. Biological limits on visual developments in primates. In: Simons K, editor. Early visual development, normal and abnormal. Oxford: Oxford University Press, 1993;296-305.

36. Ikeda H, Wright MJ. Properties of LGN cells in kittens reared with convergent squint: a neurophysiological demonstration of amblyopia. Exp Brain Res 1976; 25:63-77. 
37. Ikeda H, Tremain KE. Amblyopia occurs in retinal ganglion cells in cats reared with convergent squint without alternating fixation. Exp Brain Res 1979; 35:559-82.

38. Cleland BG, Crewther DP, Crewther GS, Mitchell DE. Normality of spatial resolution of retinal ganglion cells in cats with strabismic amblyopia. J Physiol (Lond) 1982;326:235-49.

39. Crewther SG, Crewther DP. Neural site of strabismic amblyopia in cats: X-cell acuities in the LGN. Exp Brain Res 1988;72:503-9.

40. Hess RF, Campbell FW, Greenhalgh T. On the nature of the neural abnormality in human amblyopia: neural aberrations and neural sensitivity loss. Pflugers Arch 1978;377:201-7.

41. Levi DM, Klein S. Hyperacuity and amblyopia. Nature 1982;298:268-70.

42. Swindale NV, Mitchell DE. Comparison of receptive field properties of neurons in area 17 of normal and bilaterally amblyopic cats. Exp Brain Res 1994; 99:399-410.

43. Chino YM, Shansky MS, Jankowski WL, Banser FA. Effects of rearing kittens with convergent strabismus on development of receptive-field properties in striate cortex neurons. J Neurophysiol 1983;50:265-86.

44. Yinon U, Auerbach E, Blank M, Friesenhausen J. The ocular dominance of cortical neurons in cats developed with divergent and convergent squint. Vision Res 1975;15:1251-6.

45. Berman N, Murphy EH. The critical period for alteration in cortical binocularity resulting from divergent and convergent strabismus. Dev Brain Res 1982;2:181-202.

46. Freeman RD, Tsumoto T. An electrophysiological comparison of convergent and divergent strabismus in the cat: electrical and visual activation of single cortical cells. J Neurophysiol 1983;49:238-53.

47. Kalil RE, Spear PD, Langsetmo A. Response properties of striate cortex neurons in cats raised with divergent or convergent strabismus. J Neurophysiol 1984;52:514-37.

48. Eckhorn R, Bauer R, Jordan W, Brosch M, Kruse W, Munk M, et al. Coherent oscillations: a mechanism of feature linking in the visual cortex? Biol Cybern 1988;60:121-30.

49. Gray CM, König P, Engel AK, Singer W. Oscillatory responses in cat visual cortex exhibit inter-columnar synchronizations which reflects global stimulus properties. Nature 1989;338:334-7.

50. Engel AK, König P, Gray CM, Singer W. Stimulus dependent neuronal oscillations in cat visual cortex: intercolumnar interaction as determined by crosscorrelation analysis. Eur J Neurosci 1990;2:588-606.

51. Singer W. Search for coherence: a basic principle of cortical self-organization. Neurosci Concepts 1990;1: $1-26$.

52. König P, Engel AK, Löwel S, Singer W. Squint affects synchronization of oscillatory responses in cat visual system. Eur J Neurosci 1993;5:501-8.

53. Löwel S, Singer W. Selection of intrinsic horizontal connections in the visual cortex by correlated neuronal activity. Science 1992;255:209-12.

54. Nelson JI. Binocular vision: disparity detection and anomalous correspondence. In: Edwards K, Llewellyn R, editors. Optometry. London: Butterworth, 1988: 217-37.

55. Schor CM. Binocular sensory disorders. In: Regan D, editor. Vision and visual dysfunction, vol 9: Binocular vision. London: Macmillan Press, 1991:179-223.
56. Travers T. Suppression of vision in squint and its association with retinal correspondence and amblyopia. Br J Ophthalmol 1938;22:577-604.

57. Sireteanu R, Fronius M. Naso-temporal asymmetries in human amblyopia: consequence of long-term interocular suppression. Vision Res 1981;21:1055-63.

58. Sireteanu R. Binocular vision in strabismic humans with alternating fixation. Vision Res 1982;22:889-96.

59. Sireteanu R. Human amblyopia: consequence of chronic interocular suppression. Human Neurobiol 1982;1:31-3.

60. Barlow HB, Blakemore C, Pettigrew JD. The neural mechanism of binocular depth perception. J Physiol (Lond) 1967;193:327-42.

61. Pettigrew JD, Nikara T, Bishop PO. Binocular interaction on single units in cat striate cortex: simultaneous stimulation by single moving slit with receptive fields in correspondence. Exp Brain Res 1968;6:391-410.

62. Ohzawa I, Freeman RD. The binocular organization of simple cells in the cat's visual cortex. J Neurophysiol 1986;56:221-42.

63. Ohzawa I, Freeman RD. The binocular organization of complex cells in the cat's visual cortex. J Neurophysiol 1986;56:243-59.

64. Sengpiel F, Blakemore C. Interocular control of neuronal responsiveness in cat visual cortex. Nature 1994;368:847-50.

65. Sengpiel F, Blakemore C, Harrad R. Interocular suppression in the primary visual cortex: a possible neural basis of binocular rivalry. Vision Res 1995; 35:179-95.

66. Leopold DA, Logothetis NK. Cell activity reflects monkey's perception during binocular rivalry. Invest Ophthalmol Vis Sci 1995;36:S813.

67. Holopigian K, Blake R, Greenwald MJ. Clinical suppression and amblyopia. Invest Ophthalmol Vis Sci 1988;29:444-51.

68. Livingstone MS, Hubel DH. Segregation of form, colour, movement and depth: anatomy, physiology and perception. Science 1988;240:740-9.

69. Jampolsky A. Characteristics of suppression in strabismus. Arch Ophthalmol 1955;54:683-96.

70. Thiele A, Bremmer F, Ilg UJ, Hoffmann K-P. Response properties of neurons in cortical areas V1, MT and MST of a monkey with late-onset strabismus. Eur J Neurosci Suppl 1992;5:263.

71. Sengpiel F, Kind P, Harrad RA, Blakemore C. Effects of induced strabismus and of dark-rearing on interocular interactions in cat area 17. In: Elsner $\mathrm{N}$, Heisenberg M, editor. Gene - brain - behaviour (Proceedings of the 21st Göttingen Neurobiology Conference). Stuttgart: Thieme, 1993:433.

72. Chino YM, Smith EL III, Yoshida K, Cheng H, Hamamoto J. Binocular interactions in striate cortical neurons of cats reared with discordant visual inputs. J Neurosci 1994;14:5050-67.

73. Freeman RD, Ohzawa I. Monocularly deprived cats: binocular tests of cortical cells reveal functional connections from the deprived eye. J Neurosci 1988; 8:2491-506.

74. Rauschecker JP. Mechanisms of visual plasticity: Hebb synapses, NMDA receptors and beyond. Physiol Rev 1991;71:587-615.

75. Sengpiel F, Freeman TCB, Blakemore C. Interocular suppression in cat striate cortex is not orientation selective. Neuroreport 1995;6:2235-9.

76. Ts'o D, Gilbert CD, Wiesel TN. Relationships between horizontal connections and functional architecture in cat striate cortex as revealed by cross-correlation 
analysis. J Neurosci 1986;6:1160-70.

77. Schwarz C, Bolz J. Functional specificity of a longrange horizontal connection in cat visual cortex: a cross-correlation study. J Neurosci 1991;11:2995-3007.

78. Albus $\mathrm{K}$, Wahle $\mathrm{P}$. The topography of tangential inhibitory connections in the postnatally developing and mature striate cortex of the cat. Eur $\mathbf{J}$ Neurosci 1994;6:779-92.
79. Kisvárday ZF, Eysel UT. Functional and structural topography of horizontal inhibitory connections in cat visual cortex. Eur J Neurosci 1993;5:1558-72.

80. Kisvárday ZF, Kim D-S, Eysel UT, Bonhoeffer T. Relationship between lateral inhibitory connections and the topography of the orientation map in cat visual cortex. Eur J Neurosci 1994;6:1619-32. 